\title{
Erratum to: Guidelines on the clinical use for the detection of neutralizing antibodies (NAbs) to IFN beta in multiple sclerosis therapy: report from the Italian Multiple Sclerosis Study group
}

\author{
Antonio Bertolotto - Marco Capobianco $\cdot$ Maria Pia Amato $\cdot$ Elisabetta Capello $\cdot$ Ruggero Capra $\cdot$ \\ Diego Centonze $\cdot$ Maria Di Ioia $\cdot$ Antonio Gallo $\cdot$ Luigi Grimaldi $\cdot$ Luisa Imberti $\cdot$ Alessandra Lugaresi \\ Chiara Mancinelli · Maria Giovanna Marrosu · Lucia Moiola · Enrico Montanari · Silvia Romano • \\ Luigina Musu • Damiano Paolicelli · Francesco Patti - Carlo Pozzilli · Silvia Rossi - Marco Salvetti · \\ Gioachino Tedeschi $\cdot$ Maria Rosaria Tola $\cdot$ Maria Trojano $\cdot$ Mauro Zaffaroni $\cdot$ Simona Malucchi
}

Published online: 2 February 2014

(C) Springer-Verlag Italia 2014

\section{Erratum to: Neurol Sci}

DOI 10.1007/s10072-013-1616-1

Unfortunately one of the co-author's name was incorrectly published in the original publication. The name of the author should read as Maria Trojano instead of Maria Troiano.
The online version of the original article can be found under doi:10.1007/s10072-013-1616-1.

\footnotetext{
A. Bertolotto $\cdot$ M. Capobianco $\cdot$ S. Malucchi $(\bowtie)$ Neurologia 2-CRESM, AOU San Luigi, Orbassano, Italy

e-mail: simona.malucchi@gmail.com
}

\section{P. Amato}

Section Neurosciences, Department NEUROFARBA, University of Florence, Florence, Italy

\section{E. Capello}

Department of Neuroscience, Rehabilitation, Ophthalmology, Genetics, Maternal and Child Health (DINOGMI), University of Genoa, Genoa, Italy

\section{R. Capra}

Centro Sclerosi Multipla, Spedali Civili, Brescia, Italy

D. Centonze $\cdot$ S. Rossi

Centro Sclerosi Multipla, Università Tor Vergata, Rome, Italy

M. Di Ioia · A. Lugaresi

Dipartimento di Neuroscienze E Imaging, Centro Sclerosi Multipla, Università “G. d'Annunzio" Chieti, Chieti, Italy

\section{A. Gallo $\cdot$ G. Tedeschi}

II Division of Neurology, Second University of Naples, Naples, Italy

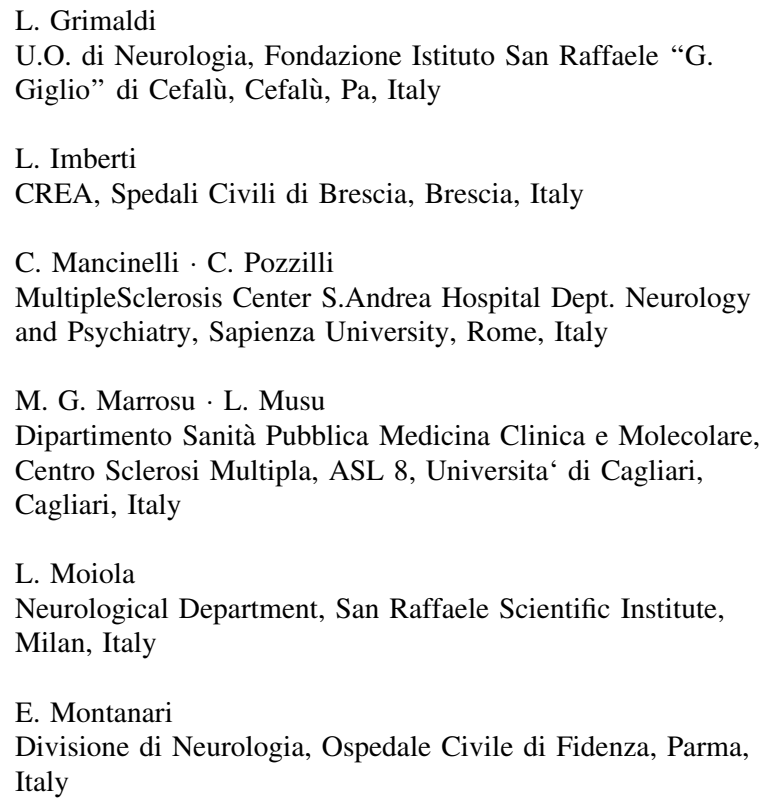


S. Romano $\cdot$ M. Salvetti

Neurology and Department of Neurosciences, Mental Health and

Sensory Organs, Centre for Experimental Neurological

Therapies (CENTERS), Sapienza University, S. Andrea

Hospital-site, Rome, Italy

D. Paolicelli $\cdot$ M. Trojano

Department of Basic Medical Sciences, Neurosciences and Sense

Organs, University of Bari Aldo Moro, Bari, Italy

\section{F. Patti}

Department of Neurosciences, University of Catania, Catania, Italy

M. R. Tola

U.O. di Neurologia, Dipartimento Neuroscienze/Riabilitazione, AOU di Ferrara, Ferrara, Italy

M. Zaffaroni

Centro Studi Sclerosi Multipla, Ospedale di Gallarate, Gallarate, Italy 